\title{
HerzMobil, an Integrated and Collaborative Telemonitoring-Based Disease Management Program for Patients With Heart Failure: A Feasibility Study Paving the Way to Routine Care
}

Elske Ammenwerth $^{1^{*}}$, Dr, FACMI, MIAHSI; Robert Modre-Osprian ${ }^{2 *}$, Dr; Bettina Fetz ${ }^{3}$, RN; Susanne Gstrein ${ }^{3}$, BSc; $^{2}$ Susanne Krestan ${ }^{3}$, RN; Jakob Dörler ${ }^{4}$, Dr; Peter Kastner ${ }^{2}$, MSc; Stefan Welte ${ }^{5}$, MSc; Clemens Rissbacher ${ }^{3}$, Dr; Gerhard Pölzl $^{4}$, Dr, FESC, FHFA

\footnotetext{
${ }_{1}^{1}$ Institute of Medical Informatics, UMIT - University for Health Sciences, Medical Informatics and Technology, Hall in Tirol, Austria

${ }^{2}$ Center for Health \& Bioresources, AIT Austrian Institute of Technology, Graz, Austria

${ }^{3}$ Tyrolean Health Care Fund, Innsbruck, Austria

${ }^{4}$ Clinical Division of Cardiology and Angiology, Medical University of Innsbruck, Innsbruck, Austria

${ }^{5}$ Center for Health \& Bioresources, AIT Austrian Institute of Technology, Hall in Tirol, Austria

*these authors contributed equally
}

\section{Corresponding Author:}

Elske Ammenwerth, Dr, FACMI, MIAHSI

Institute of Medical Informatics

UMIT - University for Health Sciences, Medical Informatics and Technology

Eduard Wallnöfer Zentrum 1

Hall in Tirol, 6060

Austria

Phone: 43508648 ext 3809

Fax: 43508648673809

Email: elske.ammenwerth@umit.at

\begin{abstract}
Background: Heart failure is a major health problem associated with frequent hospital admissions. HerzMobil Tirol is a multidisciplinary postdischarge disease management program for heart failure patients to improve quality of life, prevent readmission, and reduce mortality and health care costs. It uses a telemonitoring system that is incorporated into a network of specialized heart failure nurses, physicians, and hospitals. Patients are equipped with a mobile phone, a weighing scale, and a blood pressure and heart rate monitor for daily acquisition and transmission of data on blood pressure, heart rate, weight, well-being, and drug intake. These data are transmitted daily and regularly reviewed by the network team. In addition, patients are scheduled for 3 visits with the network physician and 2 visits with the heart failure nurse within 3 months after hospitalization for acute heart failure.

Objective: The objectives of this study were to evaluate the feasibility of HerzMobil Tirol by analyzing changes in health status as well as patients' self-care behavior and satisfaction and to derive recommendations for implementing a telemonitoring-based interdisciplinary disease management program for heart failure in everyday clinical practice.

Methods: In this prospective, pilot, single-arm study including 35 elderly patients, the feasibility of HerzMobil Tirol was assessed by analyzing changes in health status (via Kansas City Cardiomyopathy Questionnaire, KCCQ), patients' self-care behavior (via European Heart Failure Self-Care Behavior Scale, revised into a 9-item scale, EHFScB-9), and user satisfaction (via Delone and McLean System Success Model).

Results: A total of 43 patients joined the HerzMobil Tirol program, and of these, 35 patients completed it. The mean age of participants was 67 years (range: 43-86 years). Health status (KCCQ, range: 0-100) improved from 46.2 to 69.8 after 3 months. Self-care behavior (EHFScB-9, possible range: 9-22) after 3 months was 13.2. Patient satisfaction in all dimensions was 86\% or higher. Lessons learned for the rollout of HerzMobil Tirol comprise a definite time schedule for interventions, solid network structures with clear process definition, a network coordinator, and specially trained heart failure nurses.
\end{abstract}

Conclusions: On the basis of the positive evaluation results, HerzMobil Tirol has been officially introduced in the province of Tyrol in July 2017. It is, therefore, the first regular financed telehealth care program in Austria. 
(JMIR Cardio 2018;2(1):e11) doi: 10.2196/cardio.9936

\section{KEYWORDS}

heart failure; telemedicine; delivery of health care, integrated; program evaluation

\section{Introduction}

\section{Heart Failure as a Major Public Health Problem}

Heart failure is approaching epidemic proportions worldwide and represents a major public health problem. Prevalence of heart failure is estimated to be $1 \%$ to $2 \%$ of the adult population, rising to $10 \%$ and more in persons aged 70 years and older [1,2]. Heart failure is the leading cause of hospitalization among elderly patients [3]. Rates of death and readmission remain high despite considerable advances in medical therapy. Mortality rate within the first year approaches $40 \%$, and up to $50 \%$ of patients are readmitted within 6 months of discharge [4-6]. Repeat hospitalizations are associated with higher mortality and contribute substantially to the enormous overall economic burden of the disease [7]. The risk of readmission and death is greatest in the early period after discharge [7-9]. These findings suggest a role for increased surveillance in the early postdischarge period of greatest vulnerability after heart failure admission. It is estimated that up to two-thirds of readmissions for acute heart failure are triggered by potentially remediable factors including "poor discharge planning, nonadherence to recommendations regarding diet and medical treatment, inadequate follow-up, poor social supports, and delays in seeking medical attention" [10].

\section{Heart Failure Disease Management Programs}

Multidisciplinary postdischarge disease management programs have been established to prevent readmission and to reduce mortality and health care costs. A recent systematic review of 47 trials took into account the heterogeneity in models of care used in different studies: multiprofessional heart failure clinics, multiprofessional follow-up without heart failure clinics, telephone contact, primary care follow-up, and enhanced patient self-care [11]. In this review, home-visiting programs and clinic-based multidisciplinary programs reduced all-cause readmission within 3 to 6 months by $25 \%$ and $30 \%$, respectively. Comparable results have also been reported in elderly patients $[12,13]$. Interestingly, a more recent review published by Ong et al showed no significant differences in 30-day readmission rate or 180-day mortality, but a significant difference in 180-day quality of life between the intervention group comprising nursing-lead phone calls and telemonitoring and the usual care group [14].

On the basis of this evidence, the European Society of Cardiology recommends heart failure care delivered in a multidisciplinary program with high priority [15]. The fundamental role of heart failure nurses is particularly emphasized [16]. In addition, a recent position paper of the Austrian Society of Cardiology recommends multidisciplinary disease management programs with monitoring of high-risk heart failure patients [17]. Exact workflow definition and the specific role of participating stakeholders in a multidisciplinary telemonitoring-based disease management program, however, still have to be defined.

HerzMobil Tirol is such a multidisciplinary disease management program for heart failure care. It was developed and implemented in the Austrian province of Tyrol.

\section{Objectives}

The objectives of this study were to evaluate the feasibility of HerzMobil Tirol by analyzing changes in health status as well as patients' self-care behavior and satisfaction and to derive recommendations for implementing a telemonitoring-based interdisciplinary disease management program for heart failure in everyday clinical practice.

\section{Methods}

\section{HerzMobil Tirol}

HerzMobil Tirol is a multidimensional postdischarge disease management program for heart failure patients using a telemedical monitoring system incorporated in a comprehensive network of specialized heart failure nurses, private practice physicians, and 3 secondary and 1 tertiary referral centers. The aim of HerzMobil Tirol is to achieve relevant and stable impact on readmission rates, mortality, quality of life, and overall health care costs.

The program builds on several pillars: patient education to improve patient empowerment; patient-held mobile phone for daily data acquisition and transmission of blood pressure, heart rate, weight, well-being, and drug intake; physician-controlled telemonitoring of these data; nurse-led care for early detection of imminent decompensation; continuous optimization of guideline-based heart failure therapy for long-term stabilization; and finally, network communication to assure comprehensive heart failure management across venues.

The program was gradually developed, with all phases accompanied by program evaluation. First, between 2010 and 2015, shared decision making, responsibilities and liabilities of stakeholders, workflow and communication, information technology infrastructure, inclusion and exclusion criteria, duration and intensity, organizational integration, health care cost-effectiveness analysis, remuneration of stakeholders, and business models were implemented, evaluated, and continuously improved. A total of 137 patients were managed in these early phases of the HerzMobil Tirol program.

\section{Disease Management Processes in HerzMobil Tirol}

All participants of HerzMobil Tirol (physicians and nurses) communicate regularly to ensure optimal patient treatment without delay. Relevant information is shared on a Web-based telehealth software [18]. Figure 1 shows details of the process of patient management. 
Figure 1. Integrated care process of HerzMobil Tirol. NT-proBNP: N-terminal prohormone of brain natriuretic peptide; HF: heart failure.

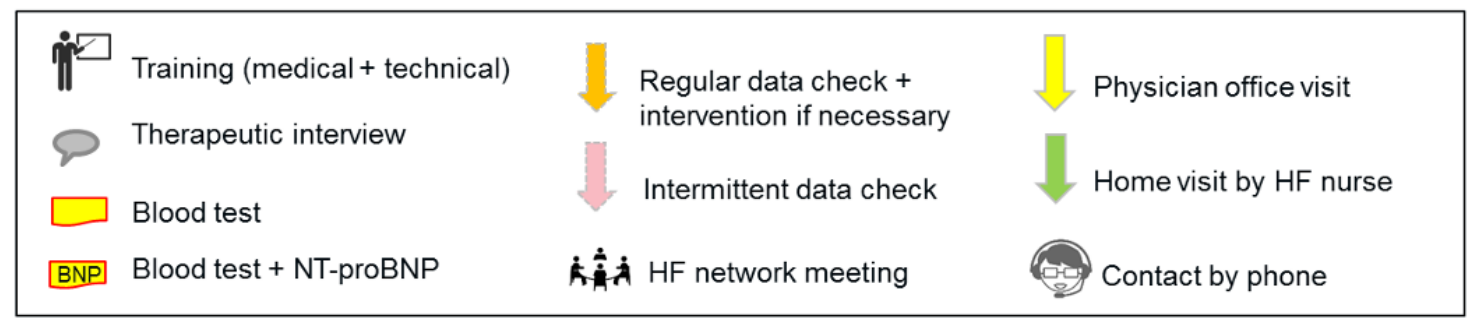

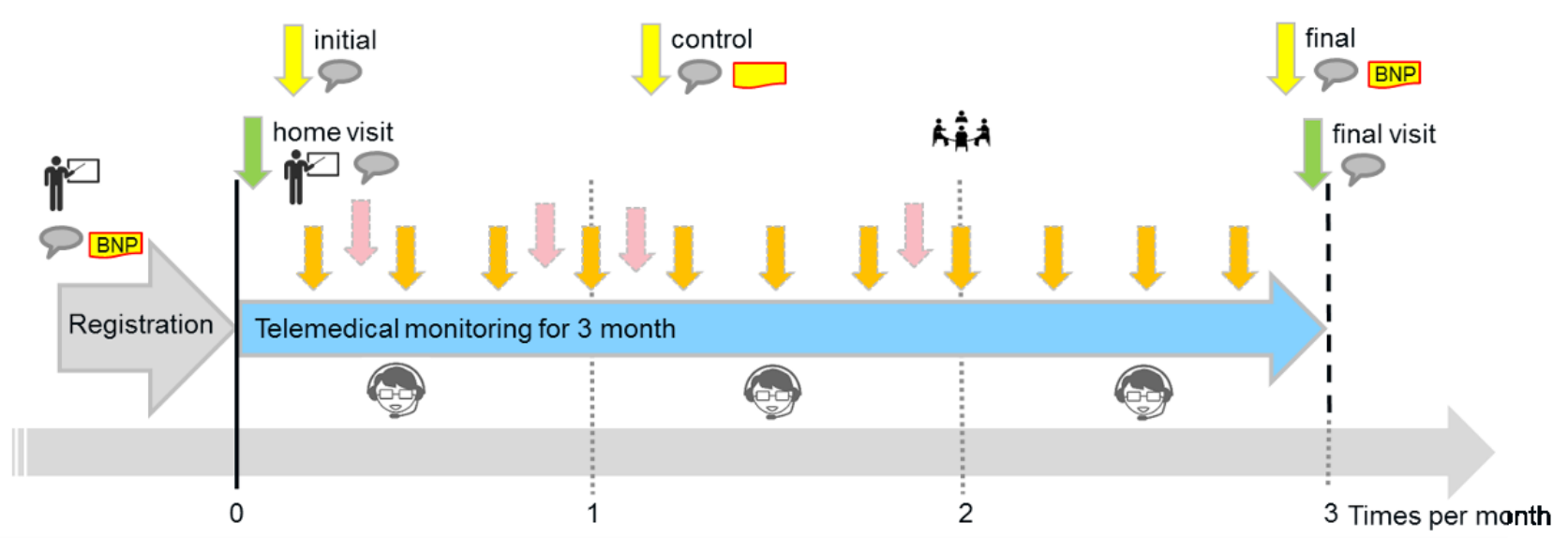

Heart failure patients enter the HerzMobil Tirol program after being hospitalized for acute heart failure. On discharge, each patient is assigned to one of the network physicians in private practice. This network physician supervises the heart failure management of the patient and optimizes the therapy. Discharge information from the hospital is communicated to the assigned network physician via the telehealth software.

Within HerzMobil Tirol, patients are supervised for 3 months. This period can be prolonged for another 3 months in case of heart failure instability. Over these 3 months, the network physician reviews telemedical patient data (blood pressure, heart rate, weight, well-being, and drug intake) and commentaries of the heart failure nurse at least once a week (regular data check). Out-of-limit data that are detected automatically by the telehealth system are highlighted and reviewed daily so that interventions, for example, adjustment of diuretics, can be taken immediately (intermittent data check).

Follow-up face-to-face visits of the patient with the network physician are scheduled 1, 4, and 12 weeks after discharge. Blood tests, for example, renal function tests, electrolytes, and $\mathrm{N}$-terminal prohormone of brain natriuretic peptide, taken at hospital discharge and follow-up visits at the physician's office allow for targeted optimization of medical therapy.

After entering the program, although the patient is still in the hospital, a heart failure nurse provides patient education both on the disease as well as on the mobile technology. During the 3 months of monitoring, these nurses are also responsible for compliance monitoring, phone contact with patients if required, and adjustments of medical therapy according to instructions of network physicians. To support this, a home visit by the heart failure nurse is scheduled immediately after discharge to finalize disease- and equipment-related education and to make sure that prescribed medication is available.
After 3 months, at the end of the managed care program, structured transfer of patients to regular care is organized.

Regular heart failure network meetings of all stakeholders (physicians and nurses) are scheduled every 3 months to support the exchange of experiences and the optimization of the technical and organizational network.

\section{Telemedical Technology in HerzMobil Tirol}

HerzMobil Tirol uses an integrated concept called Keep-In-Touch (KIT) to facilitate efficient and reliable daily data documentation and transfer of blood pressure, heart rate, weight, well-being, and drug intake [19]. Every patient included in HerzMobil Tirol is provided a blood pressure and heart rate monitor and a weighing scale as well as a near-field communication-enabled mobile phone for daily data acquisition and transmission.

Heart failure nurses introduce patients to this equipment. Patients can call a helpdesk in case of technical problems. As most of the patients are elderly patients, the dialogue-oriented and process-supporting KIT technology and the mobile app are designed to support the patients at home in easy and secure handling of the daily data acquisition process [20].

To identify upcoming adverse events, signal processing algorithms are used to analyze the transmitted physiological data [20]. Automatic event detection that identifies both missing values as well as off-limit measurements indicates the need for immediate actions and fosters attention to those patients who might need early therapeutic intervention. The limits used for automatic event detection are individually defined and regularly adapted for each patient by the network physician.

The Web-based telehealth software is made available to all stakeholders (network physicians, nurses, helpdesk, and network coordinator) and supports their individual tasks by user-specific 
dashboards (Figure 2). Each user can access the telehealth software using personal login information, normally via their computer or laptop. After login, a list of patients who are monitored by the user (eg, all patients being monitored by the network physician as user) is displayed. After selecting a patient, the monitoring interface, as shown in Figure 2, is shown.

The Web-based telehealth software is not integrated into the electronic health records of the various users because of the heterogeneity of the used software products (all hospitals and all network physicians are using electronic health records from different vendors).

\section{Data Collection}

Ethical approval for the study was given by the ethical committee of the Medical University of Innsbruck.

During the prospective, pilot, single-arm study, the network comprised 16 physicians and 5 nurses. Patients hospitalized at the University Hospital of Innsbruck for acute heart failure during January and September 2016 were assigned to HerzMobil Tirol irrespective of the underlying heart disease. Patients with end-stage heart failure or relevant comorbidities (Charlson comorbidity score $>5$ ) associated with a life expectancy of less than 6 months or patients who could not use the provided devices were excluded from the program.

Patients were recruited during hospitalization and were surveyed at baseline as well as after 3 months using the following instruments:
- Kansas City Cardiomyopathy Questionnaire (KCCQ) is a validated 23-item survey to assess the health status and quality of life of patients with cardiomyopathy [21]. It addresses physical limitation, symptoms, self-efficacy, social limitations, and quality of life. A summary score and a clinical score are calculated. The scores range from 0 to 100, with higher scores indicating better health status.

- European Heart Failure Self-Care Behavior Scale (EHFScB-9) is a 9-item scale to assess self-care behavior of heart failure patients. It has been validated [22] and is available in German [23]. Overall self-care behavior is calculated by adding the scores of the 9 items, leading to scores from 9 to 45 . A score of 9 indicates best self-care behavior.

- Information System Success Model Survey was developed based on the Delone and McLean Information System Success Model [24]. It consists of questions on the 6 dimensions: information quality (3 items), system quality (6 items), service quality (4 items), intention to use (7 items), user satisfaction ( 3 items), and net benefits ( 9 items). The instrument also contains 6 open questions on benefit and possibilities for improvements. The instrument was adapted from earlier studies, but is not formally validated.

In addition, the project team conducted 3 workshops with all network physicians and nurses to discuss the feasibility of HerzMobil and to derive lessons learned for future improvements of both organizational and technical components.

Figure 2. Stakeholder-specific dashboards of the Web-based telehealth system HerzMobil. Top chart: systolic (red) and diastolic (blue) blood pressure with daily measurement (-) and target range (red/blue area). Middle chart: heart rate with daily measurements (green dots) and target range (yellow area). Bottom chart: weight with daily measurements (blue dots) and target range (yellow area). Red exclamation marks: automatic alert on an event that has to be dealt with (eg, sudden change of weight or reaching predefined alerting values). Upper right: demographics of the patients (name, birth date, and address) as well as number of weekly data transmissions. Lower right: communication notes between physicians and nurses on this patient.

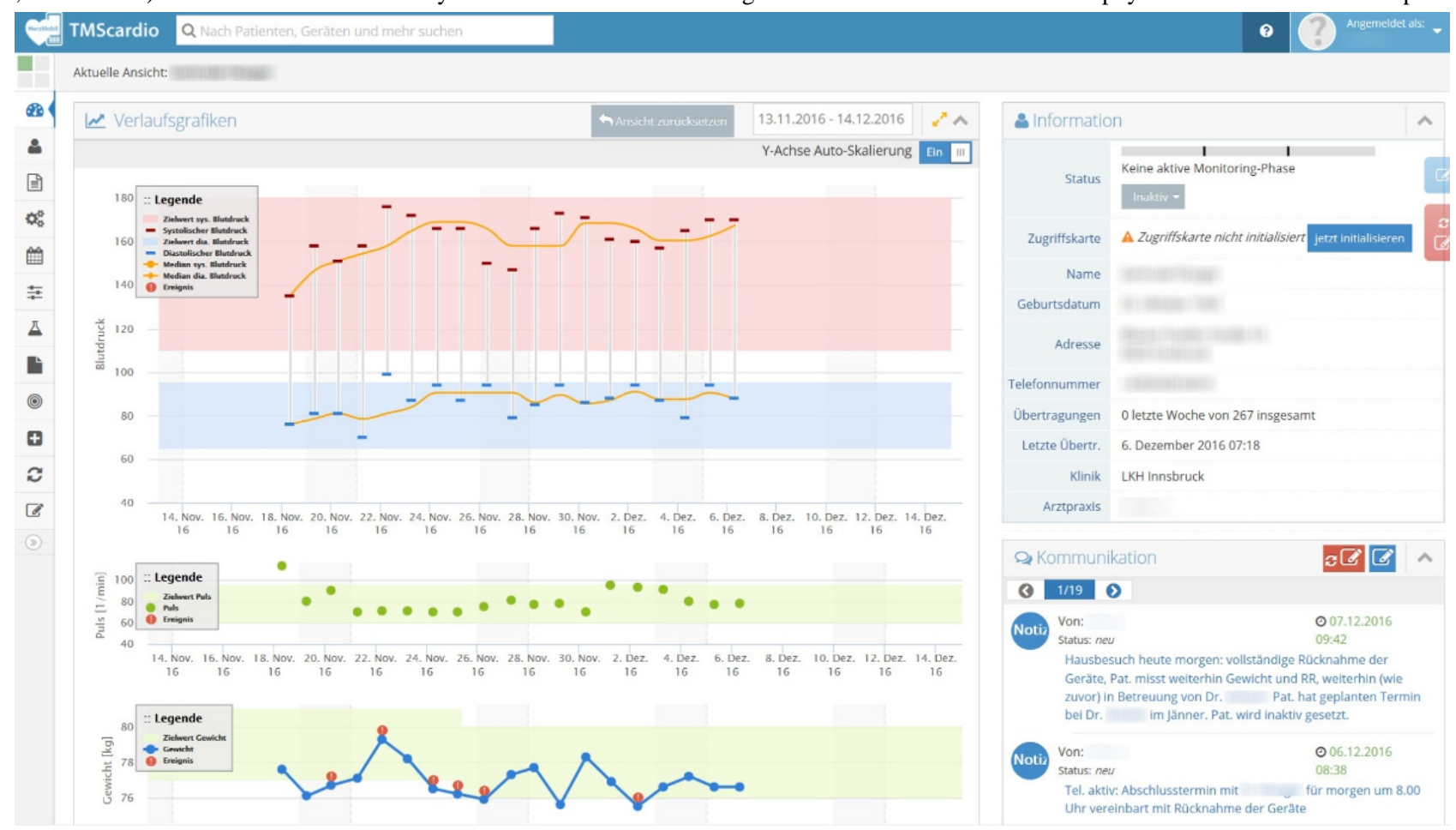




\section{Results}

\section{Participants}

A total of 50 patients were eligible and contacted between January and September 2016. From these patients, 43 patients agreed to join the HerzMobil Tirol program. Seven patients left the program because of incompliance or technical problems. Moreover, 1 patient died before completion. Of the remaining 35 patients, 28 completed all questionnaires. Mean age of these patients was 67 years (range: 43-86 years), 23 were male, and 5 were female (see Table 1 ).

The patients had between none and 6 comorbidities (median: $2)$, mostly history of myocardial infarction (7 patients), light liver disease (5 patients), and peripheral arterial occlusive disease (5 patients). A total of 15 of the 28 patients $(15 / 28,54 \%)$ had used computers before the study, and 16 patients $(16 / 28$, $57 \%$ ) had used mobile phones.

\section{Kansas City Cardiomyopathy Questionnaire Health Status}

The overall summary KCCQ score (range: 0-100) increased from 46.2 at baseline to 69.8 after 3 months. The clinical summary KCCQ score increased from 51.4 to 77.3 (see Figure 3). Physical limitation increased from 51.1 to 77.5 ; self-efficacy increased from 63.0 to 88.4; quality of life increased from 42.9 to 69.1 ; social limitation increased from 38.5 to 51.1 ; and the total symptom score increased from 51.6 to 76.3 . All changes were significant $(P<.05)$ with the exception of social limitation.

Table 1. Number and age of participants.

\begin{tabular}{llll}
\hline Participants & All & Male & Female \\
\hline Recruited for study, n (\%) & $50(100)$ & $37(74)$ & $5(26)$ \\
Never beginner, n (\%) & $7(100)$ & $8(10)$ & $2(29)$ \\
Dropped out or died during study, n (\%) & $35(100)$ & $5(62)$ & $3(38)$ \\
Completed participation in study, n (\%) & $67.1(43-86)$ & $65.6(43-6)$ & $71.5(43-85)$ \\
Mean age of participants in years (minimum-maximum) & $28(80)$ & $23(85)$ & $5(63)$ \\
Completed all questionnaires (return rate) & & $83)$ \\
\hline
\end{tabular}

Figure 3. Change of health status (Kansas City Cardiomyopathy Questionnaire score; $n=28 ; 0=$ minimum, 100=maximum) at baseline and after 3 months.

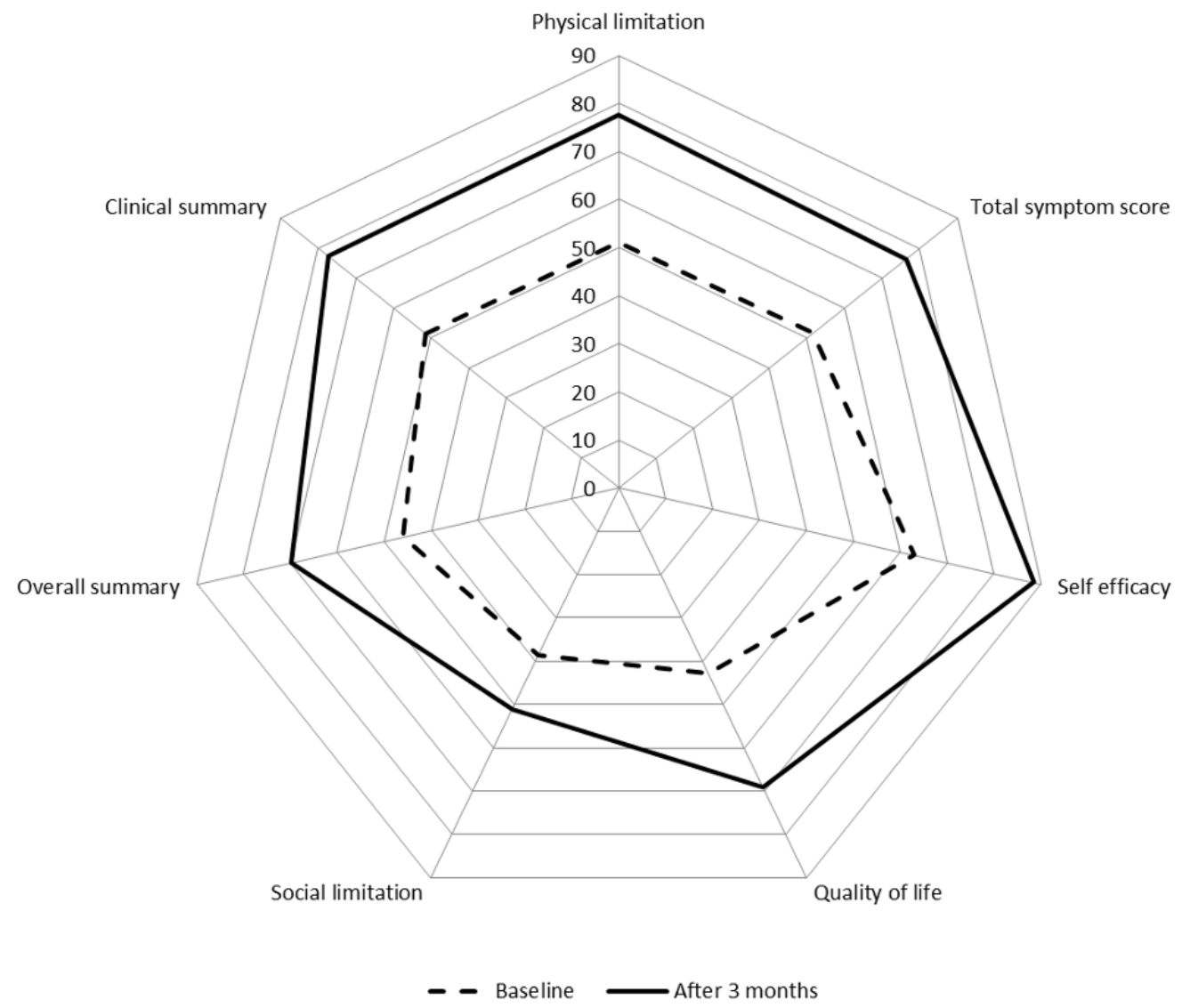




\section{European Heart Failure Self-Care Behavior Scale, Revised Into a 9-Item Scale, Self-Care Behavior}

EHFScB-9 self-care behavior score after 3 months was 13.2 (SD 4.3), range was 9 to 22, with $9=$ best self-care behavior (see Figure 4).

\section{Patient Satisfaction}

In all 6 dimensions of the Information System Success Model survey (range 0\%-100\%), mean results were $86 \%$ and higher (Figure 5), indicating high patient satisfaction.
A majority of patients $(25 / 28,89 \%)$ considered HerzMobil Tirol a good idea (D2, Figure 6) and would recommend it to others (D3). More than half of the patients $(15 / 28,53 \%)$ indicated that they would like to continue to use the telemonitoring system (F4). After 3 months, the majority of patients $(22 / 28,79 \%)$ indicated that they feel confident to be able to take care of their health without telemonitoring (F3).

In free text answers, 11 patients stated that they feel more secure because of the daily monitoring, and 4 patients stated that they are more confident in actively managing their disease. Moreover, 6 patients noted that the technology was somewhat unreliable and that the mobile phone was too complex for them.

Figure 4. European Heart Failure Self-Care Behavior scale, revised into a 9-item scale, self-care behavior scores (n=29) after 3 months.

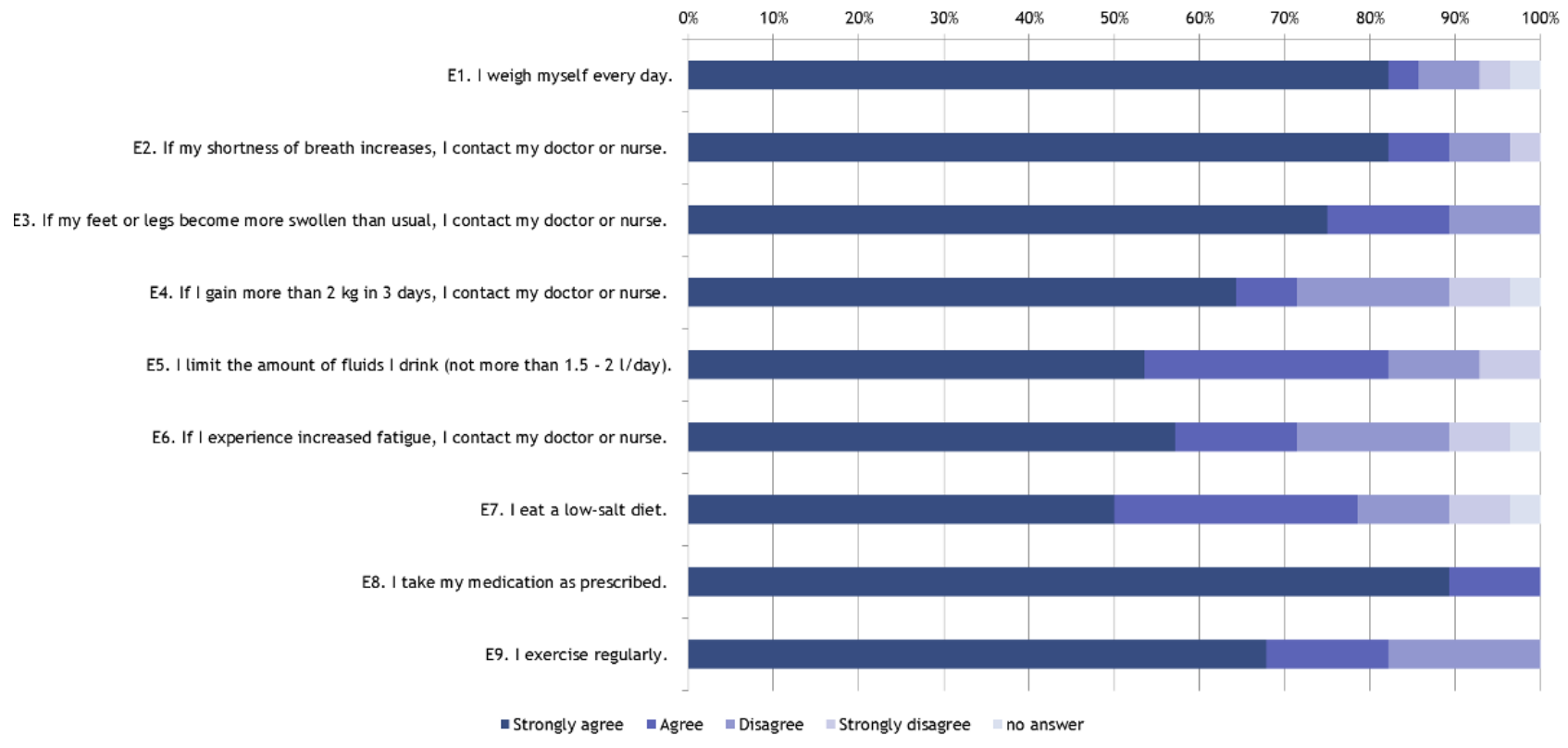

Figure 5. Aggregated results from the Information System Success Model survey $(\mathrm{n}=28)$ after 3 months (minimum=0\%, maximum=100\%). Information quality $95.2 \%$; system quality $92.3 \%$; service quality $95.8 \%$; user satisfaction $95.2 \%$; net benefit $87.1 \%$; and intention to use $86 \%$.

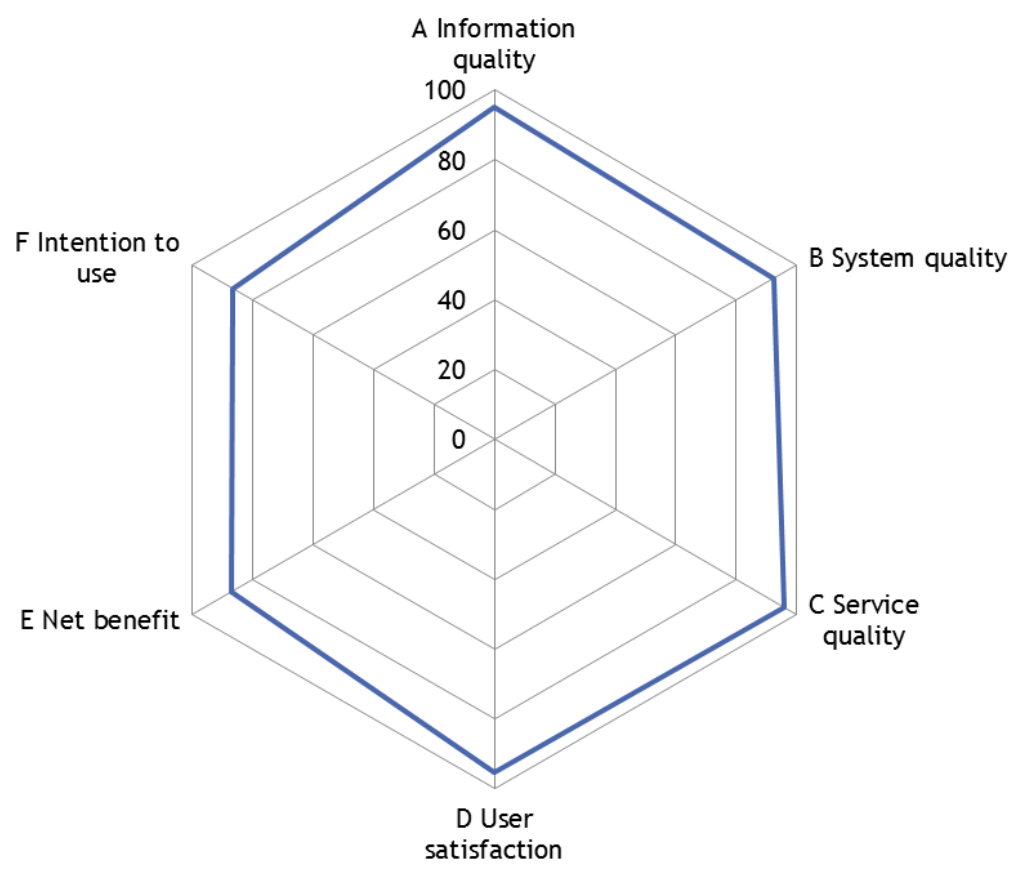


Figure 6. Selected items from the Information System Success Model survey $(\mathrm{n}=28)$ after 3 months.

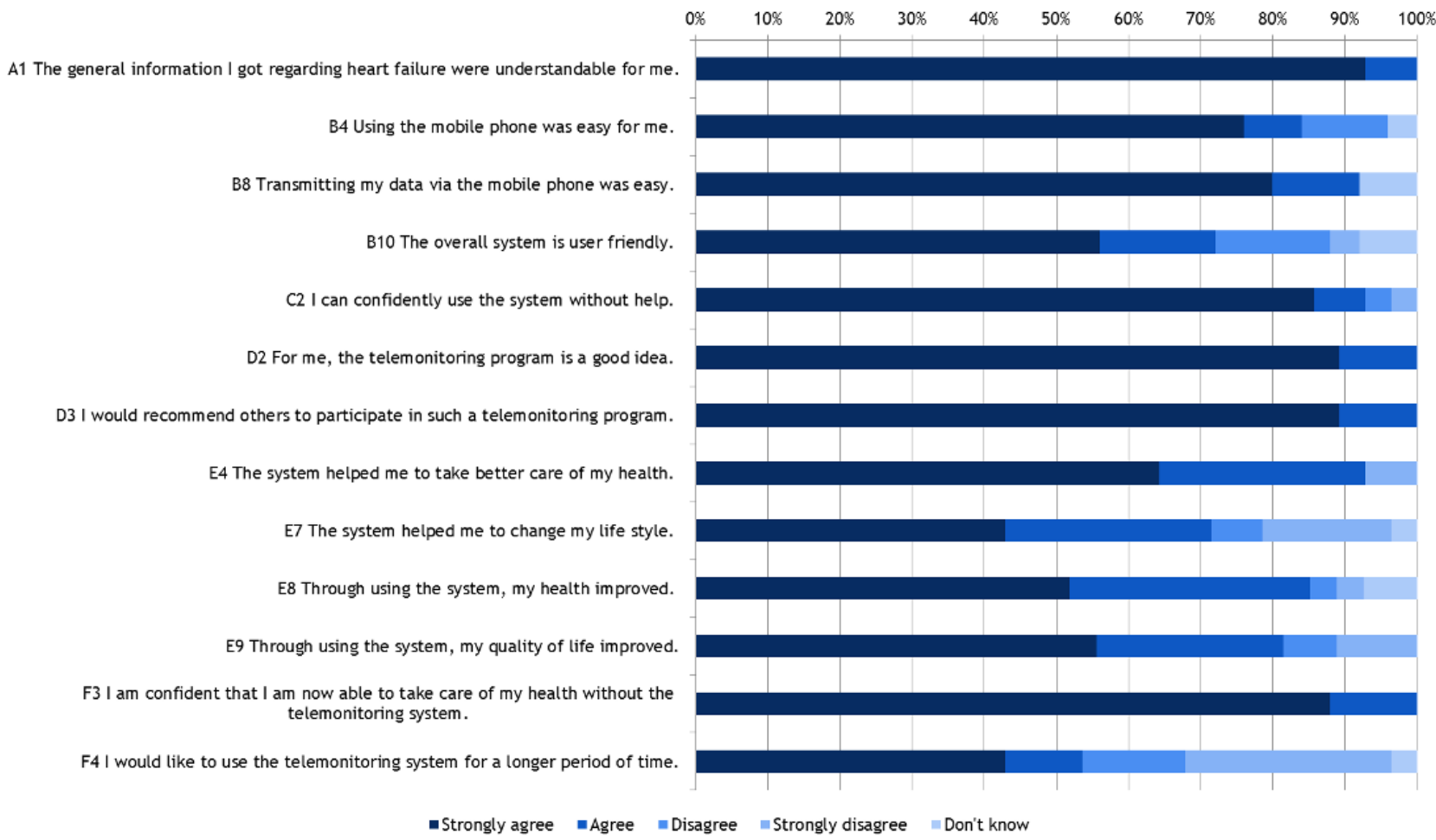

\section{Discussion}

Several studies already showed that home telemonitoring could reduce hospitalizations and mortality for patients with heart failure [25]. Here, we show our data on feasibility of home telemonitoring as part of a multidisciplinary postdischarge disease management program in everyday clinical practice. In addition, we will present lessons learned derived from this pilot study for further rollout of the program in the state of Tyrol.

\section{Summary of Study Results}

Our results indicate that health status clearly improved in the most vulnerable phase of heart failure, as indicated by improved KCCQ and EHFScB-9 scores. Patients reported a high level of satisfaction with the quality of the system and the support and with the individual benefits of participation and showed good self-care behaviors after 3 months. In particular, the elderly patients seemed quite capable of using the mobile phone for data acquisition and data transmission. Only 5 patients (18\%) stated that they received help from relatives. Thus, although age is often seen as a barrier to the use of technology [26], we found that this barrier can be addressed with patient education, good support by relatives, and a dedicated helpline. It must be noted, however, that 7 patients left the HerzMobil Tirol program because of in compliance or technical problems and were thus not included in data analysis.

\section{HerzMobil Tirol as a Disease Management Program}

The transition between hospital and home after admission for acute heart failure is a vulnerable period marked by unplanned emergency room visits, hospital readmissions, and a high risk of death $[8,9]$. The importance of effective communication between health care professionals involved with inpatient and community care [27], intense patient education to improve self-empowerment, constant medication reconciliation and therapy optimization according to prevailing guidelines, structured outpatient follow-up for early indicators of clinical decompensation for a seamless transition from the hospital to community, and the central role of specialized heart failure nurses in this complex interplay is well recognized [11,27-29]. A reliable and stable telemedical network is the facilitator for such an organizational network.

HerzMobil Tirol is designed as such a multidisciplinary postdischarge disease management program for heart failure patients using a telemedical monitoring system incorporated in a comprehensive network of specialized heart failure nurses, nonhospital-based physicians, and referral centers. The telemonitoring system HerzMobil Tirol relays physiological data, information on patient's symptoms, and drug adherence for review to the health care professionals. The gradual development of the program finally resulted in the decision to offer a concentrated 3-month health care service covering the most vulnerable phase after discharge.

Nonhospital-based network physicians and heart failure nurses play a central role in this network program. Shared decision making and effective communication between heart failure nurses and network physicians are based on the well-defined workflow and responsibilities. Intense education of patient and their families within and outside the hospital by trained heart failure nurses and structured follow-up by network physicians are central for sustained disease stabilization. Meticulous preand postcare evaluation of patients ensures quality control, thus continuous optimization of the program.

\section{Comparison With Other Studies}

Health status of patients at discharge in HerzMobil Tirol measured by the KCCQ score was lower than that in other 
studies, indicating better health status. Improvement in the KCCQ score after 3 months was higher than that in other studies (Figure 7): Boyne et al measured KCCQ for 382 patients with stable heart failure who received 6 months of daily telemonitoring, combined with 2 hospital check visits [30]. Quian et al measured KCCQ for 1427 patients with recent inpatient treatment for heart failure who received 6 months of daily telemonitoring [31]. Bekelmann et al [32] measured KCCQ for 392 patients with known heart failure who participated in a collaborative heart failure network combined with 6 months of telemonitoring. Köberich et al [33] measured KCCQ for 122 patients who were hospitalized due to heart failure, received special training, and then a 3-month phone-based monitoring. Although the studies of Boyne and Bekelmann included patients with stable heart failure, Qian and Köberich included patients with unstable heart failure, which is comparable with HerzMobil Tirol. Still, patients in HerzMobil Tirol showed the strongest improvement of the KCCQ score (Figure 7).

Self-care behavior measured by the EHFScB-9 after 3 months of care (mean: 13.2) indicated better self-care behavior compared with the following studies: Lee et al reported a mean EHFScB-9 score of 18.1 for 200 heart failure patients [22]. Koeberich et al found a mean EHFScB-9 score of 19.9 for 109 heart failure patients [23]. The same group showed a mean EHFScB-9 score of 19.6 at baseline and of 16.5 after 3 months for a group of 58 discharged heart failure patients who received special training, combined with telephone support over 3 months [33]. Comparatively, the mean EHFScB-9 score in HerzMobil Tirol patients of care was lower.

\section{Limitations of the Study}

The study was designed as a pilot study without a control group. Hence, analyses are limited to pre- and postcomparisons and comparison with published data. It cannot be entirely excluded that improvement in health status after 3 months is part of a gradual stabilization after hospitalization. Yet, comparison with published data from other studies suggests a better outcome of patients in HerzMobil Tirol with regard to health status and self-care behavior.

Self-care behaviors were measured only at the end of the third month. To address this limitation, self-care behaviors of HerzMobil Tirol patients were also compared with data from other studies.

Outcome was measured using survey instruments. As of now, no long-term evaluation of rehospitalization and other adverse events is available for HerzMobil Tirol.

\section{Implications and Recommendations for Practice}

Telemonitoring for heart failure patients is not new, and several studies have established the feasibility of these approaches and its positive impact on clinical outcome [34-36]. However, HerzMobil Tirol is a telemonitoring project that was able to transform from a pilot study to a routine care project. On the basis of the experiences in transferring from a pilot to routine care, several lessons can be derived. They were developed in repeated workshops with network physicians and network nurses and may be useful for other disease management programs for heart failure. These recommendations are also supported by a recent position paper on disease management of heart failure of the Austrian Society of Cardiology that also stresses these aspects [17].

Figure 7. Change of health status (Kansas City Cardiomyopathy Questionnaire, KCCQ score) in HerzMobil Tirol at baseline and after 3 months in comparison with 4 other studies.

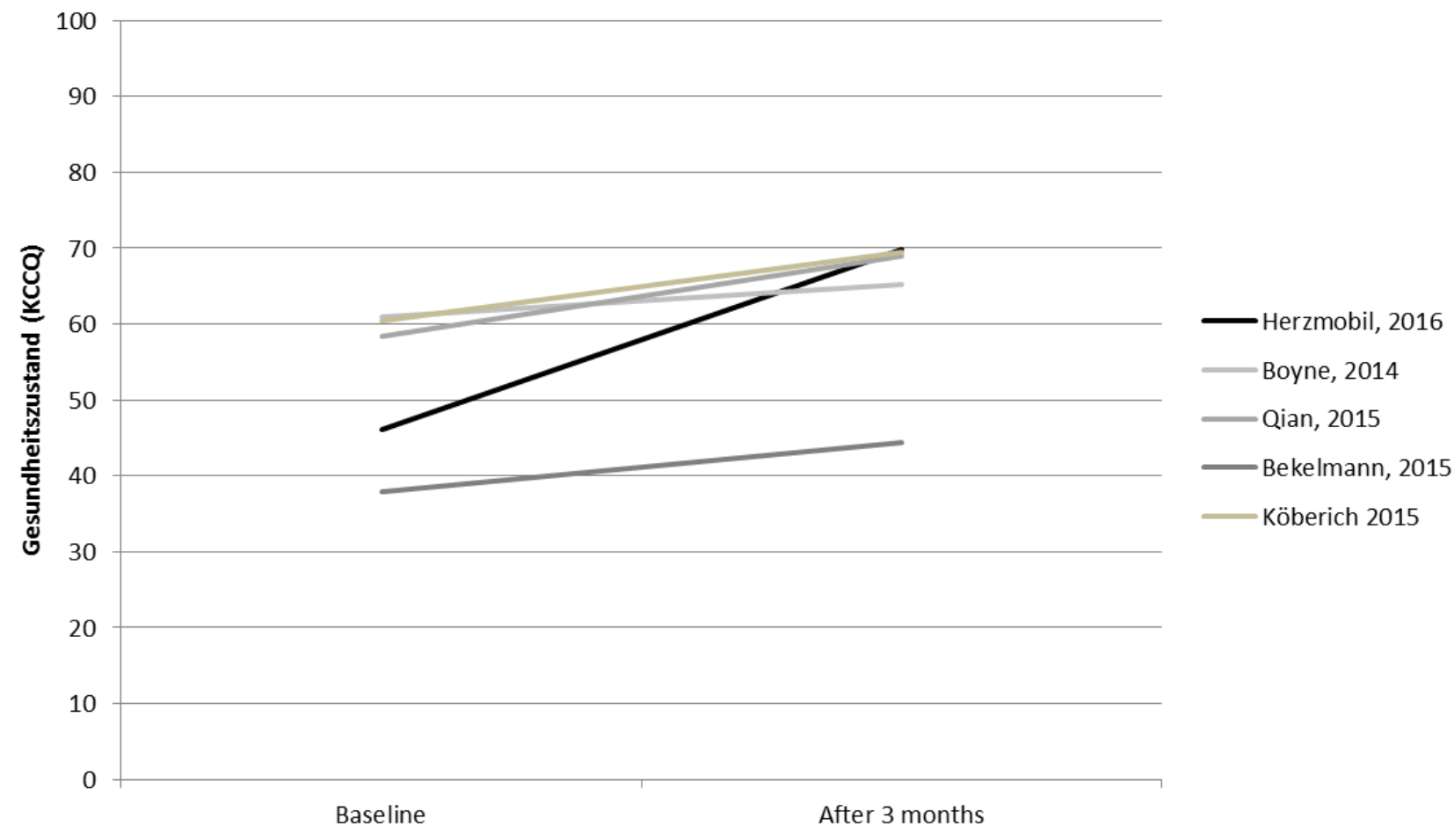


First, it is crucial to decide on the temporal positioning of managed care in the trajectory of heart failure. In the vulnerable period that is directly after discharge, focus in HerzMobil Tirol is on the seamless transition from the hospital to the telemedical network and on a 3-month monitoring. Effective communication between health care providers in various sectors is mandatory in this phase. This requires a well-organized telemedical platform that can be easily and safely accessed by all stakeholders. In contrast, in programs supporting the chronic phase, the length of telemonitoring is often not clearly defined, and communication between sectors of care, in general, is less challenging here.

Second, in the vulnerable period, patient education and constant optimization of disease-modifying therapy are particularly important. Defining the predominant gaps in health care in a region and building HerzMobil Tirol on existing health care infrastructures are essential for a high acceptance by payers and caregivers.

Third, a solid network structure and well-defined processes are more important than the specific telemonitoring tools that are used. For example, remote follow-up either by telephone or by telemonitoring must be made available in a well-functioning network of health care professionals to ensure constant review and timely response.

Fourth, the implementation process must be clear and transparent and avoid work overload, particularly to the heart failure nurses. A dedicated program coordinator is helpful to orchestrate all stakeholders and manage efficient cooperation of all partners. This strengthens the acceptance by health care professionals. In addition, legal aspects and adequate remuneration of stakeholders have to be settled.

Fifth, because of the central role of heart failure nurses, providing specialized training for nurses is a mandatory prerequisite before commencing such a program. In addition, meticulous introduction of all stakeholders into the processes and clear definition of the particular role as well as constant training for the entire personnel has to be organized.

Sixth, the first months after commencing a program are mostly dedicated to the optimization of organizational issues. Hence, it is helpful to avoid inclusion of multimorbid patients in this initial phase to not push the boundaries of the program by too complex interventions.

Summarizing, to establish a multidisciplinary postdischarge disease management network for heart failure patients, a large number of organizational, technical, legal, and economic questions have to be answered and tested in pilot projects before such a program can be transferred from a project status into routine care. In the case of HerzMobil Tirol, this process took 6 years overall.

\section{Conclusions}

The steady increase in the number of chronic patients due to the demographic trend and the ongoing medical progress shows the weaknesses of the Austrian health care system. A historically grown separation between in-patient and out-patient care leads to an insufficient consideration of the medical needs of patients along with their carers.

Telehealth care, as HerzMobil Tirol, can to some extent solve this problem and should be seen as a strategical investment to improve medical care. The telemedical information and communication technologies used in HerzMobil Tirol can help to overcome organizational and sectoral boundaries.

The role and competencies of the involved health professionals also have to be defined. HerzMobil Tirol has highlighted, for example, that specialized heart failure nurses will gain importance. Especially for Austria, which has a lot of potential for improvements in this field, this is an important insight.

Telehealth care is far more than a technology project. Instead, it enables lasting innovations for the health care system. HerzMobil Tirol showed that telehealth care is a trigger for change and innovation in the health care system. This is an important finding, especially in complex and change-resistant systems such as the health care system.

HerzMobil Tirol was officially introduced in the province of Tyrol in July 2017. This is the first telehealth care program in Austria regularly financed by health insurances. On the basis of the positive experiences, the province of Tyrol is also willing to establish further telehealth care projects in other relevant indications. The rollout in Tyrol will be done gradually. At the moment, specific regions are selected where more HerzMobil Tirol networks of hospital(s), physicians, and nurses are being established. Experiences from the already running regions are made available to the new regions to facilitate fast rollout. Further evaluation of long-term impact of HerzMobil Tirol is planned. Experiences of HerzMobil Tirol are also made available to other Austrian federal states, yet Austrian-wide rollout is dependent on political and financial decisions that are outside the control of the project team.

\section{Acknowledgments}

The authors would like to thank all physicians and nurses who participated in the collaborative HerzMobil Tirol network for their support and enthusiasm.

\section{Conflicts of Interest}

HerzMobil Tirol is funded by the state of Tyrol. RMO and GP are project managers of HerzMobil Tirol. Other authors have no conflicts of interest to declare.

\section{References}


1. Benjamin EJ, Blaha MJ, Chiuve SE, Cushman M, Das SR, Deo R, American Heart Association Statistics Committee and Stroke Statistics Subcommittee. Heart disease and stroke statistics-2017 update: a report from the American Heart Association. Circulation 2017 Mar 07;135(10):e146-e603 [FREE Full text] [doi: 10.1161/CIR.0000000000000485] [Medline: 28122885]

2. Redfield MM, Jacobsen SJ, Burnett Jr JC, Mahoney DW, Bailey KR, Rodeheffer RJ. Burden of systolic and diastolic ventricular dysfunction in the community: appreciating the scope of the heart failure epidemic. J Am Med Assoc 2003 Jan 08;289(2):194-202. [Medline: 12517230]

3. Azad N, Lemay G. Management of chronic heart failure in the older population. J Geriatr Cardiol 2014 Dec;11(4):329-337 [FREE Full text] [doi: 10.11909/j.issn.1671-5411.2014.04.008] [Medline: 25593582]

4. Chun S, Tu JV, Wijeysundera HC, Austin PC, Wang X, Levy D, et al. Lifetime analysis of hospitalizations and survival of patients newly admitted with heart failure. Circ Heart Fail 2012 Jul 01;5(4):414-421 [FREE Full text] [doi: 10.1161/CIRCHEARTFAILURE.111.964791] [Medline: 22556322]

5. Gheorghiade M, Vaduganathan M, Fonarow GC, Bonow RO. Rehospitalization for heart failure: problems and perspectives. J Am Coll Cardiol 2013 Jan 29;61(4):391-403 [FREE Full text] [doi: 10.1016/j.jacc.2012.09.038] [Medline: 23219302]

6. Krumholz HM, Merrill AR, Schone EM, Schreiner GC, Chen J, Bradley EH, et al. Patterns of hospital performance in acute myocardial infarction and heart failure 30-day mortality and readmission. Circ Cardiovasc Qual Outcomes 2009 Sep;2(5):407-413 [FREE Full text] [doi: 10.1161/CIRCOUTCOMES.109.883256] [Medline: 20031870]

7. Solomon SD, Dobson J, Pocock S, Skali H, McMurray JJ, Granger CB, Candesartan in Heart Failure: Assessment of Reduction in Mortality and Morbidity (CHARM) Investigators. Influence of nonfatal hospitalization for heart failure on subsequent mortality in patients with chronic heart failure. Circulation 2007 Sep 25;116(13):1482-1487 [FREE Full text] [doi: 10.1161/CIRCULATIONAHA.107.696906] [Medline: 17724259]

8. Desai AS. The three-phase terrain of heart failure readmissions. Circ Heart Fail 2012 Jul 01;5(4):398-400 [FREE Full text] [doi: 10.1161/CIRCHEARTFAILURE.112.968735] [Medline: 22811548]

9. Cowie MR, Anker SD, Cleland JG, Felker GM, Filippatos G, Jaarsma T, et al. Improving care for patients with acute heart failure: before, during and after hospitalization. ESC Heart Fail 2014 Dec;1(2):110-145. [doi: 10.1002/ehf2.12021] [Medline: 28834628]

10. Desai AS. Home monitoring heart failure care does not improve patient outcomes: looking beyond telephone-based disease management. Circulation 2012 Feb 14;125(6):828-836 [FREE Full text] [doi: 10.1161/CIRCULATIONAHA.111.031179] [Medline: 22331920]

11. Feltner C, Jones CD, Cené CW, Zheng Z, Sueta CA, Coker-Schwimmer EJ, et al. Transitional care interventions to prevent readmissions for persons with heart failure: a systematic review and meta-analysis. Ann Intern Med 2014 Jun 3;160(11):774-784. [doi: 10.7326/M14-0083] [Medline: 24862840]

12. Pedone C, Rossi FF, Cecere A, Costanzo L, Antonelli Incalzi R. Efficacy of a physician-led multiparametric telemonitoring system in very old adults with heart failure. J Am Geriatr Soc 2015 Jun;63(6):1175-1180. [doi: 10.1111/jgs.13432] [Medline: 26031737]

13. Scherr D, Kastner P, Kollmann A, Hallas A, Auer J, Krappinger H, MOBITEL Investigators. Effect of home-based telemonitoring using mobile phone technology on the outcome of heart failure patients after an episode of acute decompensation: randomized controlled trial. J Med Internet Res 2009 Aug 17;11(3):e34 [FREE Full text] [doi: 10.2196/jmir.1252] [Medline: 19687005]

14. Ong MK, Romano PS, Edgington S, Aronow HU, Auerbach AD, Black JT, Better Effectiveness After Transition-Heart Failure (BEAT-HF) Research Group. Effectiveness of Remote Patient Monitoring After Discharge of Hospitalized Patients With Heart Failure: The Better Effectiveness After Transition -- Heart Failure (BEAT-HF) Randomized Clinical Trial. JAMA Intern Med 2016 Mar;176(3):310-318 [FREE Full text] [doi: 10.1001/jamainternmed.2015.7712] [Medline: 26857383]

15. Ponikowski P, Voors AA, Anker SD, Bueno H, Cleland JG, Coats AJ, Authors/Task Force Members, Document Reviewers. 2016 ESC Guidelines for the diagnosis and treatment of acute and chronic heart failure: The Task Force for the diagnosis and treatment of acute and chronic heart failure of the European Society of Cardiology (ESC). Developed with the special contribution of the Heart Failure Association (HFA) of the ESC. Eur J Heart Fail 2016 Aug;18(8):891-975 [FREE Full text] [doi: 10.1002/ejhf.592] [Medline: 27207191]

16. Riley JP, Astin F, Crespo-Leiro MG, Deaton CM, Kienhorst J, Lambrinou E, et al. Heart Failure Association of the European Society of Cardiology heart failure nurse curriculum. Eur J Heart Fail 2016 Jul;18(7):736-743 [FREE Full text] [doi: 10.1002/ejhf.568] [Medline: 27220672]

17. Moertl D, Altenberger J, Bauer N, Berent R, Berger R, Boehmer A, et al. Disease management programs in chronic heart failure : position statement of the Heart Failure Working Group and the Working Group of the Cardiological Assistance and Care Personnel of the Austrian Society of Cardiology. Wien Klin Wochenschr 2017 Dec;129(23-24):869-878 [FREE Full text] [doi: 10.1007/s00508-017-1265-0] [Medline: 29080104]

18. Modre-Osprian R, Gruber K, Kreiner K, Schreier G, Poelzl G, Kastner P. Textual analysis of collaboration notes of the telemedical heart failure network HerzMobil Tirol. Stud Health Technol Inform 2015;212:57-64. [Medline: 26063258]

19. Morak J, Kumpusch H, Hayn D, Modre-Osprian R, Schreier G. Design and evaluation of a telemonitoring concept based on NFC-enabled mobile phones and sensor devices. IEEE Trans Inf Technol Biomed 2012 Jan;16(1):17-23. [doi: 10.1109/TITB.2011.2176498] [Medline: 22113811] 
20. Von der Heidt A, Ammenwerth E, Bauer K, Fetz B, Fluckinger T, Gassner A, et al. HerzMobil Tirol network: rationale for and design of a collaborative heart failure disease management program in Austria. Wien Klin Wochenschr 2014 Nov;126(21-22):734-741. [doi: 10.1007/s00508-014-0665-7] [Medline: 25392254]

21. Green CP, Porter CB, Bresnahan DR, Spertus JA. Development and evaluation of the Kansas City Cardiomyopathy Questionnaire: a new health status measure for heart failure. J Am Coll Cardiol 2000 Apr;35(5):1245-1255 [FREE Full text] [Medline: 10758967]

22. Lee CS, Lyons KS, Gelow JM, Mudd JO, Hiatt SO, Nguyen T, et al. Validity and reliability of the European Heart Failure Self-Care Behavior Scale among adults from the United States with symptomatic heart failure. Eur J Cardiovasc Nurs 2013 Apr;12(2):214-218 [FREE Full text] [doi: 10.1177/1474515112469316] [Medline: 23263273]

23. Köberich S, Glattacker M, Jaarsma T, Lohrmann C, Dassen T. Validity and reliability of the German version of the 9-item European Heart Failure Self-care Behaviour Scale. Eur J Cardiovasc Nurs 2013 Apr;12(2):150-158. [doi:

10.1177/1474515112438639] [Medline: 22396179]

24. DeLone W, McLean E. The DeLone and McLean Model of Information Systems Success: a ten-year update. J Manag Inf Syst 2003;19(4):9-30.

25. Polisena J, Tran K, Cimon K, Hutton B, McGill S, Palmer K, et al. Home telemonitoring for congestive heart failure: a systematic review and meta-analysis. J Telemed Telecare 2010;16(2):68-76. [doi: 10.1258/jtt.2009.090406] [Medline: $\underline{20008054]}$

26. Lind L, Carlgren G, Karlsson D. Old-and with severe heart failure: telemonitoring by using digital pen technology in specialized homecare: system description, implementation, and early results. Comput Inform Nurs 2016 Aug;34(8):360-368. [doi: 10.1097/CIN.0000000000000252] [Medline: 27223309]

27. Vedel I, Khanassov V. Transitional care for patients with congestive heart failure: a systematic review and meta-analysis. Ann Fam Med 2015 Nov;13(6):562-571 [FREE Full text] [doi: 10.1370/afm.1844] [Medline: 26553896]

28. Mebazaa A, Yilmaz MB, Levy P, Ponikowski P, Peacock WF, Laribi S, et al. Recommendations on pre-hospital \& early hospital management of acute heart failure: a consensus paper from the Heart Failure Association of the European Society of Cardiology, the European Society of Emergency Medicine and the Society of Academic Emergency Medicine. Eur J Heart Fail 2015 Jun;17(6):544-558 [FREE Full text] [doi: 10.1002/ejhf.289] [Medline: 25999021]

29. Strömberg A. Educating nurses and patients to manage heart failure. Eur J Cardiovasc Nurs 2002 Feb;1(1):33-40. [doi: 10.1016/S1474-5151(01)00011-1] [Medline: 14622865]

30. Boyne J, Spreeuwenberg M, Gorgels A, Vrijhoef H. Effects of Telemonitoring on Heart Failure Patients? Quality of Life and Depression Scores: a Randomised Controlled Trial. 2014 Presented at: Proceedings of TELEMED 2014, International Conference on eHealth, Telemedicine, and Social Medicine; 2014; Barcelona, Spain p. 35-43.

31. Qian F, Parzynski CS, Chaudhry SI, Hannan EL, Shaw BA, Spertus JA, et al. Racial differences in heart failure outcomes: evidence from the Tele-HF Trial (Telemonitoring to Improve Heart Failure Outcomes). JACC Heart Fail 2015 Jul;3(7):531-538 [FREE Full text] [doi: 10.1016/j.jchf.2015.03.005] [Medline: 26160368]

32. Bekelman DB, Plomondon ME, Carey EP, Sullivan MD, Nelson KM, Hattler B, et al. Primary results of the Patient-Centered Disease Management (PCDM) for Heart Failure Study: a randomized clinical trial. JAMA Intern Med 2015 May;175(5):725-732. [doi: 10.1001/jamainternmed.2015.0315] [Medline: 25822284]

33. Köberich S, Lohrmann C, Mittag O, Dassen T. Effects of a hospital-based education programme on self-care behaviour, care dependency and quality of life in patients with heart failure--a randomised controlled trial. J Clin Nurs 2015 Jun;24(11-12):1643-1655. [doi: 10.1111/jocn.12766] [Medline: 25661470]

34. Lee H, Park JB, Choi SW, Yoon YE, Park HE, Lee SE, et al. Impact of a telehealth program with voice recognition technology in patients with chronic heart failure: feasibility study. JMIR Mhealth Uhealth 2017 Oct 02;5(10):e127 [FREE Full text] [doi: 10.2196/mhealth.7058] [Medline: 28970189]

35. Bashi N, Karunanithi M, Fatehi F, Ding H, Walters D. Remote monitoring of patients with heart failure: an overview of systematic reviews. J Med Internet Res 2017 Jan 20;19(1):e18 [FREE Full text] [doi: 10.2196/jmir.6571] [Medline: 28108430]

36. Agboola S, Jethwani K, Khateeb K, Moore S, Kvedar J. Heart failure remote monitoring: evidence from the retrospective evaluation of a real-world remote monitoring program. J Med Internet Res 2015;17(4):e101 [FREE Full text] [doi: 10.2196/jmir.4417] [Medline: 25903278]

\author{
Abbreviations \\ EHFScB9: European Heart Failure Self-Care Behavior Scale \\ KCCQ: Kansas City Cardiomyopathy Questionnaire \\ KIT: Keep-In-Touch
}


Edited by $G$ Eysenbach; submitted 25.01.18; peer-reviewed by C Craven, $P$ Athilingam; comments to author 21.02.18; accepted 28.02.18; published 30.04.18

Please cite as:

Ammenwerth E, Modre-Osprian R, Fetz B, Gstrein S, Krestan S, Dörler J, Kastner P, Welte S, Rissbacher C, Pölzl G

HerzMobil, an Integrated and Collaborative Telemonitoring-Based Disease Management Program for Patients With Heart Failure:

A Feasibility Study Paving the Way to Routine Care

JMIR Cardio 2018;2(1):e11

URL: http://cardio.jmir.org/2018/1/e11/

doi: $10.2196 /$ cardio. 9936

PMID: 31758765

CElske Ammenwerth, Robert Modre-Osprian, Bettina Fetz, Susanne Gstrein, Susanne Krestan, Jakob Dörler, Peter Kastner, Stefan Welte, Clemens Rissbacher, Gerhard Pölzl. Originally published in JMIR Cardio (http://cardio.jmir.org), 30.04.2018. This is an open-access article distributed under the terms of the Creative Commons Attribution License (https://creativecommons.org/licenses/by/4.0/), which permits unrestricted use, distribution, and reproduction in any medium, provided the original work, first published in JMIR Cardio, is properly cited. The complete bibliographic information, a link to the original publication on http://cardio.jmir.org, as well as this copyright and license information must be included. 